\title{
Indocyanine green fluorescence-guided thoracoscopic pulmonary resection for intralobar pulmonary sequestration: a case report
}

\author{
Nozomu Motono* (D), Shun Iwai, Aika Funasaki, Atsushi Sekimura, Katsuo Usuda and Hidetaka Uramoto
}

\begin{abstract}
Background: The potential complications of pulmonary sequestration are serious and may include recurrent pulmonary infection, hemoptysis, and tumorigenesis. Therefore, the gold standard of treatment has been surgery. Although an adequate boundary between the nonfunctional lung and normal lung is required for the resection of pulmonary sequestration, the boundaries have been conventionally identified intraoperatively with inflation/deflation of the target segment by clamping and unclamping the relevant bronchus. The technique of visualizing the demarcation line based on near-infrared fluorescence imaging with indocyanine green was recently developed.
\end{abstract}

Case presentation: A 42-year-old Japanese woman with right Pryce III intralobar sequestration was admitted to our hospital. We planned video-assisted thoracoscopic wedge resection of the right sequestration using near-infrared fluorescence imaging with indocyanine green because of the small volume of the nonfunctional region. The aberrant artery was recognized in the pulmonary ligament; the artery was cut off after ligation. Indocyanine green at $5 \mathrm{mg} / \mathrm{body}$ was rapidly injected into the peripheral vein, and the boundary of the sequestration was clearly identified under near-infrared fluorescence imaging.

Conclusion: Near-infrared fluorescence imaging with indocyanine green is safe and useful for the identification of the boundary of a pulmonary sequestration.

Keywords: Pulmonary sequestration, Near-infrared, Indocyanine green

\section{Background}

Pulmonary sequestration is a rare congenital malformation characterized by nonfunctional lung tissue separated from the normal lung tissue and fed by an aberrant systemic artery [1]. The potential complications of pulmonary sequestration are serious and may include recurrent pulmonary infection, hemoptysis, and tumorigenesis. Therefore, the gold standard of treatment has been surgery. Although thoracotomy has conventionally been required for the resection of pulmonary sequestration, video-assisted thoracic surgery (VATS) has been increasingly frequently performed [2]. Although an adequate boundary between the nonfunctional lung

\footnotetext{
* Correspondence: motono@kanazawa-med.ac.jp

Department of Thoracic Surgery, Kanazawa Medical University, 1-1 Daigaku, Uchinada, Ishikawa 920-0293, Japan
}

and normal lung is required for the resection of pulmonary sequestration, the boundaries have been conventionally identified intraoperatively with inflation/deflation of the target segment by clamping and unclamping the relevant bronchus. The technique of visualizing the demarcation line based on near-infrared (NIR) fluorescence imaging with indocyanine green (ICG) was recently developed, and its utility was reported [3-13].

We report the safety and utility of ICG fluorescenceguided thoracoscopic pulmonary resection for intralobar pulmonary sequestration.

\section{Case presentation}

An abnormal shadow was detected in a 42-year-old Japanese woman by medical checkup X-ray and she was admitted to our hospital. She had no symptoms and had 
no medical, social, environmental, obstetrical, family and employment history. She had never smoked tobacco and she occasionally drank alcohol. Her blood pressure was $112 / 60 \mathrm{mmHg}$, pulse was 72 beats per minute, and body temperature was 36.4 degrees Celsius. She had no significant abnormal findings on physical and neurological examination. Blood cell count, liver and renal functions, and urine analysis were within normal limits. Any bacteria or fungi were not cultured by microbiological analysis of sputum. Chest computed tomography (CT) showed multicystic change in the lower lobe of her right lung and an aberrant artery arising from the descending aorta (Fig. 1a-c). Because the nonfunctional lung region was covered by normal visceral pleura, she was diagnosed as having Pryce III intralobar sequestration. One and a half months after the first visit, we planned videoassisted thoracoscopic wedge resection of the right sequestration using NIR fluorescence imaging with ICG because of the small volume of the nonfunctional region. The institutional review boards of our hospital approved the protocol (the approval number, M416), and written informed consent was obtained from this patient.

A 3-cm incision was made in the fourth intercostal space, and two additional ports were made in the seventh and ninth intercostal spaces. The aberrant artery was recognized in the pulmonary ligament (Fig. 2a) and cut off using an automatic suture device after ligation. ICG (Daiichi Sankyo Co., Ltd., Tokyo, Japan) at $5 \mathrm{mg} /$ body was rapidly injected into the peripheral vein, and her lung was observed using NIR fluorescence thoracoscopy (IMAGE1 $\mathrm{S}^{\mathrm{Tm}}$; KARL STORZ, Endoscope, Tokyo, Japan). Under the
NIR light, the boundary of the sequestration was separated into two areas and then marked on the visceral pleura with electrocautery (Fig. 2b, c). The sequestration lung was stapled based on the boundary line. The operation time was 1 hour and 26 minutes with $5 \mathrm{ml}$ of intraoperative bleeding. Cefazolin sodium at $2 \mathrm{~g} /$ day was administered into the peripheral vein for 2 days after surgery, and laboratory findings were within normal limits. Any bacteria or fungi were not cultured by microbiological analysis of lung tissue. No adverse events or complications were seen, and our patient was discharged on postoperative da y 5 . This patient has shown no complications in the 1 year since surgery.

\section{Discussion}

This report shows the safety and utility of ICG fluorescence-guided thoracoscopic pulmonary resection for intralobar pulmonary sequestration. Although several studies have reported the utility of identifying the segmental line using NIR fluorescence imaging with ICG [3-13], there are few reports in which ICG was used for identification of demarcation line of intralobar pulmonary sequestration [11]. Management of asymptomatic pulmonary sequestration is controversial. Although surgical resection of pulmonary sequestration has been recommended because of the likelihood of recurrent infection and the possibility of hemorrhage, lobectomy is often required [14]. Although thoracotomy has conventionally been required for resection of pulmonary sequestration, VATS has been increasingly frequently performed

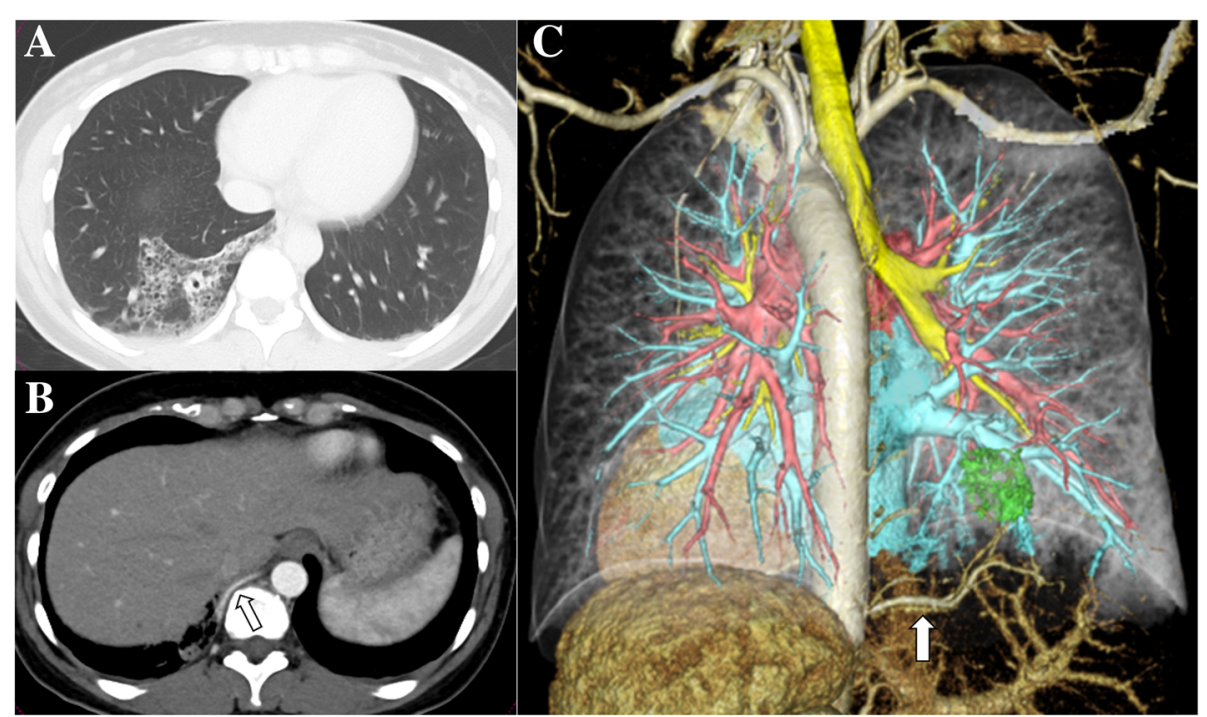

Fig. 1 a Chest computed tomography showing multicystic changes in the lower lobe of the right lung. $\mathbf{b}$ Enhanced computed tomography showing the right aberrant artery arising from the descending aorta (arrow). c Three-dimensional computed tomography showing the right aberrant artery arising from the descending aorta (arrow) 


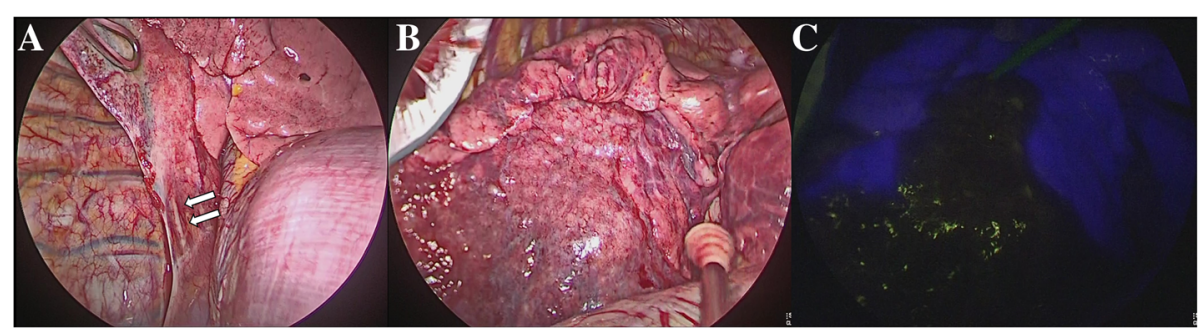

Fig. $\mathbf{2}$ a The aberrant artery flows through the pulmonary ligament (arrows). b The boundary of the sequestration is unclear. c The boundary of the sequestration is clearly indicated by indocyanine green

[15]. Sublobar resection is usually performed for small sequestration, and it is important to identify an adequate boundary. Traditionally, the boundaries were identified intraoperatively with inflation/deflation of the target segment by clamping and unclamping the relevant bronchus. However, the inflated lung may obstruct the view of the target region, particularly in VATS. The identification rate of the boundary of the target segment ranged from 90$100 \%$. ICG is generally considered safe, and the incidence of severe adverse reactions has been reported to be $0.05 \%$ $[16,17]$. In previous studies, the dose of ICG used for lung segmentectomy ranged from 0.25 to $5 \mathrm{mg} / \mathrm{kg}$ (for example 15 to $300 \mathrm{mg}$ of ICG applied to a patient weighing $60 \mathrm{~kg}$ ), and no complications were attributed to ICG $[3-6,8,12]$. However, the incidence of anaphylactic shock due to ICG used for angiography at doses of 25 to $75 \mathrm{mg}$ was reported to be $0.05 \%$ [17]. Although the dose of ICG was quite low at $5 \mathrm{mg}$ in the present case, the demarcation line of target segment was clearly identified, so this dose of ICG was sufficient for identification of the segmental line. Using such a low dose of ICG is safe, as well, by helping avoid anaphylactic shock.

The difficulty of resection for pulmonary sequestration is the identification of the aberrant artery. Most of the aberrant arteries were present in the inferior pulmonary ligament [18]. Inflammatory changes caused by recurrent infections would develop dense adhesions accompanied with proliferative vessels, and this situation might make the surgical field bloody and blurred. It is important to image the location of the target vessels; threedimensional CT was useful for identification of the aberrant artery in our case. Because the aberrant artery would be thickened or fragile due to recurrent infections, proximal ligation of the thickened or fragile aberrant artery with a stapling device before cutting it is considered to be important [18].

\section{Conclusions}

NIR fluorescence imaging with ICG was safe and useful for the identification of the boundary for wedge resection of pulmonary sequestration. Low-dose ICG might be sufficient for identification of the segmental line while still avoiding anaphylactic shock. Segmentectomy and wedge resection for small pulmonary sequestration using NIR fluorescence imaging with ICG might become a standard surgical procedure.

\section{Acknowledgements}

Not applicable.

\section{Authors' contributions}

NM designed the study, edited and performed a critical revision of the manuscript. SI, AF, AS, and KU collected data. HU contributed to the literature review and writing of the manuscript. All authors read and approved the final version of the article.

\section{Funding}

This study does not receive funding.

\section{Availability of data and materials}

Please contact the corresponding author for data requests.

\section{Ethics approval and consent to participate}

The institutional review boards of Kanazawa Medical University approved the protocol (the approval number, M416), and written informed consent was obtained from this patient.

\section{Consent for publication}

Written informed consent was obtained from the patient for publication of this case report and any accompanying images. A copy of the written consent is available for review by the Editor-in-Chief of this journal.

\section{Competing interests}

The authors declare that they have no competing interests.

Received: 27 September 2018 Accepted: 20 May 2019

Published online: 27 July 2019

\section{References}

1. Kravitz RM. Congenital malformations of the lung. Pediatr Clin N Am. 1994:41:453-72.

2. Liu C, Pu Q, Ma J, Mei J, Xiao Z, Liao H, et al. Video-assisted thoracic surgery for pulmonary sequestration compared with posterolateral thoracotomy. J Thorac Cardiovasc Surg. 2013;146:557-61.

3. Misaki N, Chang SS, Igai H, Tarumi S, Gotoh M, Yokomise H. New clinically applicable method for visualizing adjacent lung segments using an infrared thoracoscopy system. J Thorac Cardiovasc Surg. 2010;140:752-6.

4. Kasai Y, Tarumi S, Chang SS, Misaki N, Gotoh M, Go T, et al. Clinical trial of new methods for identifying lung intersegmental borders using infrared thoracoscopy with indocyanine green: comparative analysis of 2- and 1wavelength methods. Eur J Cardiothorac Surg. 2013;44:1103-7. 
5. Tarumi S, Misaki N, Kasai Y, Chang SS, Go T, Yokomise H. Clinical trial of video-assisted thoracoscopic segmentectomy using infrared thoracoscopy with indocyanine green. Eur J Cardiothorac Surg. 2014;46:112-5.

6. lizuka S, Kuroda H, Yoshimura K, Dejima H, Seto K, Naomi A, et al. Predictors of indocyanine green visualization during fluorescence imaging for segmental plane formation in thoracoscopic anatomical segmentectomy. Thorac Dis. 2016;8:985-91.

7. Kuroda H, Dejima H, Mizuno T, Sakakura N, Sakao Y. A new LigaSure technique for the formation of segmental plane by intravenous indocyanine green fluorescence during thoracoscopic anatomical segmentectomy. J Thoac Dis. 2016:8:1210-6.

8. Mun M, Okumura S, Nakao M, Matsuura Y, Nakagawa K. Indocyanine green fluorescence-navigated thoracoscopic anatomical segmentectomy. J Vis Surg. 2017;2:80.

9. Ito A, Takao M, Shimamoto A, Shimpo H. Prolonged intravenous indocyanine green visualization by temporary pulmonary vein clamping: real-time intraoperative fluorescence image guide for thoracoscopic anatomical segmentectomy. Eur J Cardiothorac Surg. 2017;52:1225-6.

10. Yamanashi K, Okumura N, Nakazono C, Matsuoka T. Surgery for intralobar pulmonary sequestration using indocyanine green fluorescence navigation: a case report. Semin Thoracic Surg. 2017;30:122-4.

11. Uramoto H, Motono N. ICG easily detects not only the segmental plane, but also the course and blood distribution of the bronchial artery "case report". Ann Med Surg. 2018;28:28-9.

12. Sekine $Y, K o E$, Oishi $H$, Miwa M. A simple and effective technique for identification of intersegmental planes by infrared thoracoscopy after transbronchial injection of indocyanine green. J Thorac Cardiovasc Surg. 2012;143:1330-5.

13. Oh S, Suzuki K, Miyasaka Y, Matsunaga T, Tsushima Y, Takamochi K. New technique for lung segmentectomy using indocyanine green injection. Ann Thorac Surg. 2013;95:2188-90.

14. Laberge JM, Bratu I, Flageole H. The management of asymptomatic congenital lung malformations. Paediatr Respir Rev. 2004;5:S305-12.

15. Albanese $\mathrm{CT}$, Rothenberg SS. Experience with 144 consecutive pediatric thoracoscopic lobectomies. J Laparoendosc Adv Surg Tech. 2007;17:339-41.

16. Hope-Ross M, Yannuzzi LA, Gragoudas ES, Guyer DR, Slakter JS, Sorenson JA, et al. Adverse reactions due to indocyanine green. Ophthalmology. 1994;10:529-33.

17. Obana A, Miki T, Hayashi K, Takeda M, Kawamura A, Mitoh T, et al. Survey of complications of indocyanine green angiography in Japan. Am J Ophthalmol. 1994;1 18:749-53.

18. Liu C, Pu Q, Ma L, Mei J, Xiao Z, Liao H, et al. Video-assisted thoracic surgery for pulmonary sequestration compared with posterolateral thoracotomy. J Thorac Cardiovasc Surg. 2013;146:557-61.

\section{Publisher's Note}

Springer Nature remains neutral with regard to jurisdictional claims in published maps and institutional affiliations.

Ready to submit your research? Choose BMC and benefit from:

- fast, convenient online submission

- thorough peer review by experienced researchers in your field

- rapid publication on acceptance

- support for research data, including large and complex data types

- gold Open Access which fosters wider collaboration and increased citations

- maximum visibility for your research: over $100 \mathrm{M}$ website views per year

At $\mathrm{BMC}$, research is always in progress.

Learn more biomedcentral.com/submissions 